\title{
DIPATI UKUR DAN JejaK PENINggalanNYa DI KECAMATAN GIPARAY KABUPATEN BANDUNG (1627-1633)
}

\author{
DIPATI UKUR AND THE TRACES OF HIS LEGACY IN CIPARAY DISTRICT, \\ BANDUNG REGENCY
}

\author{
Lasmiyati \\ Balai Pelestarian Nilai Budaya Jawa Barat \\ Jln. Cinambo 136 Ujungberung Bandung \\ e-mail: lasmiyatinizam@gmail.com
}

\begin{abstract}
Abstrak
Tokoh adalah orang yang mempunyai karisma dan hasil karya. Hasil karya seseorang dapat berupa tulisan atau pun benda peninggalan sejarah, baik sebagai tempat yang ditinggali atau pun sebagai petilasan. Dipati Ukur menjabat adipati di Tatar Ukur dan menjabat sebagai bupati wedana di Priangan (1627-1733), mengalami nasib yang malang. Ia harus menanggung pencopotan sebagai bupati wedana dan hidup berpindah-pindah, setelah adanya perselisihan dengan Mataram. Penelitian ini dilakukan untuk menjawab pertanyaan siapakah Dipati Ukur, telah berkiprah di bidang apa, dan apa peninggalannya. Metode yang digunakan adalah metode sejarah yang meliputi heuristik, kritik, interpretasi, dan historiografi. Dari hasil penelitian yang dilakukan diperoleh informasi bahwa Dipati Ukur lahir di daerah Purbolinggo Banyumas Jawa Tengah. Ia keturunan Sunan Jambu Karang. Dari pengembaraannya setelah melakukan perlawanan terhadap Belanda di Batavia, ia membuat bangunan yang saat ini menjadi benda peninggalan dan petilasannya. Salah satu bukti peninggalannya adalah Situs Bukit Cula yang ada di Kecamatan Ciparay Kabupaten Bandung.
\end{abstract}

Kata kunci: Dipati Ukur, Ciparay.

Abstract

Figures are people who have the charisma and work. The work of a person can be a text or historical relics, either as a live or as petilasan (traces of something in the past eg. buildings, etc.). Dipati Ukur served the adipati (Duke) in Tatar Ukur and served as regent wedana of Priangan (1627-1733), suffered an unfortunate fate. He must bear removal as regent wedana and nomadic, following a dispute with Mataram Kingdom. This study was conducted to answer the question who is Dipati Ukur?, has been active in what field?, and what legacy? The method used is the historical method which includes heuristics, criticism, interpretation, and historiography. The research results are to be obtained information that Dipati Ukur born in Purbolinggo Banyumas, Central Java. He was a descendant of Sunan Jambu Karang. From his wanderings after fighting a war against the Dutch in Batavia, he makes the building which is now a relic and petilasan (traces of something in the past eg. buildings, etc.). One proof of his legacy is the largest hill horn legacy in Sub-Ciparay, Bandung regency.

Keywords: Dipati Ukur, Ciparay.

\section{A. PENDAHULUAN}

Tokoh adalah orang terkemuka dan kenamaan (dalam bidang politik, kebudayaan, dan sebagainya) (Tim Penyusunan KBBI, 2011: 1476). Berbicara mengenai tokoh akan membicarakan seseorang dari lahir hingga meninggal. Dari seorang tokoh akan muncul pemikiranpemikirannya dalam setiap kesempatan, 
bahkan tatkala tokoh tersebut telah tiada ada benda atau peninggalan yang ditinggalkannya yaitu barang yang ditinggalkan, pusaka, bekas reruntuhan dari zaman dahulu, candi, dan sebagainya (Tim Penyusunan KBBI, 2011:1468).

Dipati Ukur merupakan tokoh sejarah bagi masyarakat Bandung dan sekitarnya. Pada saat ia menjabat sebagai bupati wedana di Priangan, Sultan Agung memberikan tugas kepada Dipati Ukur dan Bahureksa untuk bersama-sama mengusir Belanda di Batavia. Oleh karena terjadi miskomunikasi dengan Bahureksa, Dipati Ukur harus menanggung akibatnya. Bahureksa menganggap Dipati Ukur telah melalaikan tugas. Sejak saat itulah Dipati Ukur harus berpindah tempat untuk menghindari serangan tentara Mataram. Daerah yang telah ditempati Dipati Ukur, dibangun petilasan yang saat ini dianggap peninggalannya. Yang menjadi pertanyaan siapakah sosok Dipati Ukur, bagaimana kiprahnya, dan apa saja bentuk peninggalannya.

Dalam artikel ini penulis mencoba membahas mengenai sosok Dipati Ukur dan sekaligus menjawab permasalahan, yaitu siapakah Dipati Ukur dan apa bentuk peninggalannya. Adapun ruang lingkup tulisan ini mengambil tempat di Kecamatan Ciparay dan sekitarnya.

Tulisan mengenai Dipati Ukur telah dilakukan oleh beberapa orang baik berupa buku atau pun artikel. Tulisan terdahulu mengenai Dipati Ukur adalah Dipati Ukur, Ksatria Sejati dari Pasundan. Buku dalam bentuk cerita rakyat Jawa Barat yang ditulis A. Setiawan tahun 2006 tersebut menceritakan bahwa Raden Wangsanata adalah keturunan langsung dari Prabu Geusan Ulun raja Sumedanglarang. Ketika Wangsanata diangkat sebagai adipati di Tatar Ukur ia bernama Dipati Ukur yang membawahkan wilayah Ukur di Priangan bagian selatan. Pusat pemerintahannya di Dayeuhkolot. Ayahnya bernama Wangsajaya. Ia memberikan wejangan seandainya Wangsanata akan menjadi pemimpin agar berguru ke Mataram. Di
Mataram, ia sempat belajar kepada Sultan Agung mengenai ketatanegaraan dan agama. Akan tetapi di Mataram Wangsanata tidak bertahan lama. Ia menuju Sukapura dan Cimanganten, dan pulang ke Banjaran Kabupaten Bandung. Kemudian, ia menggantikan kedudukan uwa-nya (Wirawangsa) di Batulayang dan dipindahkan ke Tatar Ukur (sekarang sekitar Dayeuhkolot Bandung). Ketika Dipati Ukur mendapat serangan dari Bahureksa di Gunung Lumbung, Dipati Ukur mengalami kekalahan.

Tulisan lainnya adalah karya Edi S Ekadjati Ceritera Dipati Ukur Karya Sastra Sunda yang ditulis 1979. Dalam buku tersebut tertulis bahwa naskah yang mengupas mengenai Cerita Dipati Ukur terdapat delapan versi yaitu versi Galuh, Sukapura, Sumedang, Bandung, Talaga, Batavia, Banten, dan Mataram. Dari delapan versi terdapat persamaan, yaitu setelah Dipati Ukur diangkat sebagai bupati wedana, Dipati Ukur menyerang Batavia. Karena kalah ia berontak kepada Mataram. Akan tetapi karena tidak ada kesepahaman antara Dipati Ukur dengan keempat umbul bawahannya, keempat umbul bawahannya melaporkan sepak terjang Dipati Ukur kepada Sultan Agung. Di tempat persembunyiannya Dipati Ukur tertangkap oleh pasukan dari Mataram.

Tulisan lainnya adalah Sejarah

Kabupaten Bandung. Buku yang ditulis oleh Nina Herlina Lubis yang bekerja sama dengan Badan Pengembangan Informasi Daerah Bandung juga mengupas tentang Dipati Ukur. Dalam buku tersebut diceritakan bahwa Dipati Ukur bernama Wangsanata, putra Sunan Jambu Karang yang berasal dari Purbolinggo Banyumas Jawa Tengah. Oleh Mataram, Wangsanata dibawa ke Tatar Ukur. Setelah diangkat anak, Wangsanata diangkat sebagai adipati di Tatar Ukur yang kemudian dikenal dengan nama Dipati Ukur. Setelah kalah berperang di Batavia ia bersembunyi di Gunung Pongporang dan Gunung Lumbung. Kemudian ia tertangkap oleh pasukan dari Mataram. Dari beberapa 
artikel yang terdahulu, ada sisi yang kosong yaitu peninggalan atau pun petilasan Dipati Ukur yang ada di Kecamatan Ciparay Kabupaten Bandung belum ditulis.

Dalam artikel ini penulis menggunakan pendekatan sejarah biografi, yaitu catatan hidup seseorang. Kuntowidjojo mengatakan bahwa dalam setiap biografi terkandung empat permasalahan, yaitu kepribadian tokohnya, kekuatan sosial yang mendukung, lukisan sejarah zamannya, keberuntungan dan kesempatan yang datang (Kuntowidjojo, 2003: 206).

Artikel ini juga akan melihat dari sisi atau bentuk peninggalannya. Peninggalan sejarah, menurut Ekadjati, merupakan hasil dari peristiwa masa lampau yang dialami oleh manusia. Peninggalan sejarah dapat diklasifikasi ke dalam tiga bentuk, yaitu: 1) lisan (berupa cerita asal-usul, legenda, folklor dan sebagainya, dan kisah pengalaman pelaku sejarah); 2) tulisan (berupa prasasti yaitu peninggalan tertulis pada batu/logam isinya mengisahkan peringatan suatu peristiwa atau tokoh, naskah, dan dokumen); dan 3) peninggalan berupa benda ${ }^{1}$.

\section{B. METODE PENELITIAN}

Metode sejarah yang meliputi tahap heuristik, yaitu tahap mencari dan menemukan sumber, baik sumber primer

${ }^{1}$ Peninggalan sejarah berupa benda diklasifikasikan ke dalam:

1) Alat kehidupan sehari-hari; yang dibedakan atas beberapa macam seperti perkakas rumah tangga, pakaian, dan alat kecantikan/hiasan; 2) Alat upacara; alat upacara kelahiran, sunatan, perkawinan, kematian, pengobatan, pelantikan, dan peringatan-peringatan tertentu; 3) kompleks kegiatan tertentu seperti ibu kota kerajaan dan pemukiman kelompok masyarakat; 4) bangunan, seperti candi, keraton, masjid, kelenteng, pendopo kabupaten, rumah, monumen, dan sebagainya; 5) alat kehidupan manusia, seperti mobil Soekarno, tombak rajaraja, dan sebagainya (Ekadjati, 1987: 2). maupun sekunder. Pada tahap ini pencarian sumber, antara lain dilakukan di Perpustakaan Nasional Jakarta, Perpustakaan Provinsi Jawa Barat, Perpustakaan Bapusipda Jawa Barat, Perpustakaan Museum Negeri Sri Baduga Jawa Barat, dan Perpustakaan Balai Arkeologi Bandung. Setelah sumber-sumber berhasil dikumpulkan, kemudian disaring secara kritis, terutama sumber-sumber pertama, agar terjaring fakta. Langkah inilah yang disebut dengan kritik sumber baik terhadap bahan materi (ekstern) maupun terhadap substansi (isi) sumber (Sjamsuddin, 2007: 131). Setelah dilakukan kritik ekstern dan isi, langkah berikutnya adalah tahap pengelompokan fakta dalam berbagai hubungan dan formulasi dan presentasi. Hasil-hasil gabungan kedua langkah ini menghasilkan karya historiografi, yaitu merangkaikan fakta hingga menjadi tulisan sejarah.

\section{HASIL DAN BAHASAN \\ 1. Dipati Ukur \\ a. Latar Belakang}

Wangsanata (yang kemudian bernama Dipati Ukur) berasal dari Kerajaan Jambu Karang berlokasi di Purbolinggo, Banyumas Jawa Tengah. Ia keturunan Sunan Jambu Karang yang waktu itu masih beragama Budha (Pemda Kabupaten Bandung, 1974: 40). Suatu ketika, di Jambu Karang datang seorang Arab yang bernama Abdurakhman alQadri. Ia menyebarkan agama Islam di kalangan rakyat. Kiprahnya tersebut mendapat tantangan dari Sunan Jambu Karang. Beberapa waktu, Abdurakhman dapat mengislamkan Sunan Jambu Karang. Sebagai ungkapan rasa terima kasih, Abdurakhman dijodohkan dengan putri Sunan dan menggantikan kedudukan Sunan Jambu Karang sebagai raja. Selama Abdurakhman menggantikan posisi Sunan, ia mengganti namanya menjadi Pangeran Atas Angin. Pernikahan antara Pangeran Atas Angin dengan putri Sunan Jambu Karang melahirkan putra bernama Cahya Luhur yang nantinya menggantikan 
ayahnya bertahta di Jambu Karang. Putra Cahya Luhur bernama Adipati Cahyana. Pada saat itulah Jambu Karang ditundukkan oleh Mataram di bawah kepemimpinan Sutawijaya. Putra Adipati Cahyana yang bernama Wangsanata oleh Mataram disingkirkan ke Tatar Ukur yang diperintah oleh Adipati Ukur Agung (Sumantri, 1973: 28). Dalam Mangle Arum, Adipati Ukur Agung adalah kepala daerah Ukur pertama yang mengakui kekuasaan Mataram. Sesampai di Tatar Ukur, pemuda Wangsanata diasuh oleh Adipati Ukur Agung. Setelah dewasa ia dijodohkan dengan Nyai Gedeng Ukur (putri Adipati Ukur Agung). Atas persetujuan Mataram, Wangsanata menggantikan kedudukan Adipati Agung sebagai penguasa di Tatar Ukur. Sejak itulah, Wangsanata lebih dikenal dengan nama Dipati Ukur (Lubis, 2003: 13).

Bagi masyarakat Banyumas, Pangeran Jambu Karang merupakan leluhur yang menjadi asal-usul berdirinya daerah baru yakni Perdikan Cahyana Purbalingga Banyumas. Dalam cerita rakyat setempat diceritakan, Pangeran Jambu Karang merupakan tokoh dari Sunda ${ }^{2}$ yang masih beragama Budha. Ia

2 Barangkali kata "Sunda" yang dimaksud penulis adalah Galuh. Batas Kerajaan Galuh pernah diungkap dalam Cerita Ciung Wanara. Dalam cerita tersebut dikisahkan bahwa waktu yang hampir bersamaan, baginda Prabu Barma Wijaya Kusumah menerima sembah yang menggembirakan dari kedua permaisuri: keduanya tidak lagi berdatang bulan. Alangkah gembiranya baginda demi mendengar sembah itu. Nampak hidup dan bercahaya kedua pasang mata permaisuri tatkala mempersembahkan berita yang akan menyebabkan baginda bersuka cita. Akan segera datang putra mahkota yang akan melanjutkan memerintah Kerajaan Galuh yang amat subur makmur dan luas terbentang dari Laut Kidul di mana Citanduy bermuara hingga laut utara di Cipamali memuntahkan airnya yang coklat, dan Pulau Rekata yang megah menghujam ke dasar Samodera hingga Pulau Dewata di mana Gunung Agung menyundul langit (Hutomo, 1990: 6). Dalam cerita Ciung Wanara dise- diislamkan oleh Pangeran Atas Angin yang berasal dari Arab. Pangeran Atas Angin kemudian menikah dengan putri Sunan yang bernama Rubiyah Bkekti. Dari perkawinan tersebut lahir 1) Pangeran Mahdum Kusen; 2) Pangeran Makdum Madem; 3) Pangeran Makdum Omar; 4) Nyai Rubiyah Raja; dan 5) Nyai Rubiyah Sekar. Pangeran Makdum Kusen kemudian menggantikan kedudukan ayahnya. Selama kepemimpinan Makdum Kusen, Perdikan Cahyana masih dalam wilayah Pajajaran. Selanjutnya Perdikan Cahyana terlepas dari kekuasaan Sunda Pajajaran. Pangeran Makdum Kusen berputra Pangeran Makdum Jamil. Makdum Jamil berputra Pangeran Makdum Tores dan Pangeran Wali Prakosa. Pangeran Wali Prakosa kemudian mempunyai lima orang anak yaitu: 1) Nyai Suratiman; 2) Kiai Pangulu; 3) Pangeran Esthi (yang menjadi istri Pangeran Makdum Cahyana); 4) Kyai Mas Pekiringan; dan 5) Kiai Mas Akhir (Priyadi, 2001: 93). Sepeninggal Mahdum Cahyana, perdikan Cahyana terbagi-bagi menjadi beberapa daerah perdikan di Kabupaten Purbalingga. Dari babad tersebut Wangsanata tidak disebut-sebut. Dalam Sadjarah Bandung disebutkan bahwa Wangsanata dibawa ke Tatar Ukur oleh Mataram.

Tatar Ukur adalah wilayah Ukur di Priangan bagian selatan. Pusat pemerintahannya di Dayeuhkolot (Setiawan, 2006: 8). Saat ini Dayeuhkolot masuk ke dalam Kabupaten Bandung. Dahulu, di daerah Ukur terdapat sembilan umbul $^{3}$ yaitu Batulayang, Saunggantang,

butkan bahwa batas wilayah Kerajaan Galuh adalah Cipamali (sekarang Brebes). Diperkirakan Purbalingga Banyumas waktu itu masuk wilayah Kerajaan Galuh.

${ }^{3}$ Umbul adalah kepala rakyat (Suryaningrat, 1982: 41). Sebelum terbentuknya Kabupaten Bandung, Tumenggung Wiraangun-angun menjabat sebagai Mantri Agung. Kepalakepala Priangan yang ada di bawah kekuasaan Wiraangun-angun adalah Demang 
Taraju, Kahuripan, Medang, Sasigar, Malangbong, Mengger, dan Ukur. Sobana mengatakan bahwa semula daerah Bandung merupakan daerah Kerajaan Timbanganten ${ }^{4}$. Pada pertengahan abad ke-15, Kerajaan Timbanganten diperintah secara turun-temurun oleh Prabu Pandaan Ukur, Dipati Ukur Agung, dan Dipati Ukur. Dalam Mangle Arum yang ditulis oleh Nina Herlina Lubis bahwa Adipati Ukur Agung adalah kepala daerah Ukur pertama yang mengakui kekuasaan Mataram atas daerahnya. Ia adalah kepala daerah Ukur yang terlebih dahulu menganut agama Islam. Dalam Naskah Sadjarah Bandung disebutkan bahwa Kerajaan Timbanganten beribu kota di Tegalluar (terletak di lereng Gunung Malabar, dahulu perbatasan antara Distrik Banjaran dan Distrik Cipeujeuh). Diperkirakan Tatar Ukur masuk dalam wilayah Kerajaan Timbanganten yang saat itu berada di wilayah Tarogong Kabupaten Garut.

Pada masa pemerintahan Dipati Ukur, luas wilayah Tatar Ukur mencakup sebagian besar wilayah di Jawa Barat, yang terdiri atas sembilan daerah yang disebut Ukur Sasanga (Ziaulhaq, 2007: 99), yaitu Ukur Bandung (wilayah Banjaran dan Cipeujeuh), Ukur Pasirpanjang (wilayah Majalaya dan Tanjungsari), Ukur Biru (wilayah Ujungberung Wetan), Ukur Kuripan (wilayah Ujungberung Kulon, Cimahi, dan Rajamandala), Ukur Curugagung (wilayah Cihea), Ukur Aranon (wilayah Wanayasa), Ukur Sagaraherang (wilayah Pamanukan

Timbanganten, Tumenggung Batulayang, Ngabehi Kahuripan, Natalaya Tarogong, Ngabehi Mangunyuda Curug Agung, Wirapati, Ngabehi Maruyung, dan ibu kota tempat bersemayamnya Wirangun-angun sendiri. Sebutan Mantri Agung pada Tumengung Wiraangun-angun, karena ia adalah penguasa yang membawahi mantrimantri lainnya atau umbul (Sumantri, 1973: 49).

${ }^{4}$ Hardjasaputra, dalam $h t t p / / w w w . b a n d u n g k a b$. go.id). dan Ciasem), Ukur Nagara Agung (wilayah Gandasoli, Adiarsa, Sumedangan), dan Ukur Batulayang (wilayah Kopo, Rongga, dan Cisondari) ${ }^{5}$. Saat ini wilayah Ukur Sasangan tersebut meliputi, kota dan Kabupaten Bandung, Kota Cimahi, Kabupaten Subang, Kabupaten Sumedang, dan Kabupaten Karawang.

Kerajaan Sumedanglarang yang didirikan oleh Prabu Tajimalela berkedudukan di Tembong Agung. Prabu Tajimalela digantikan oleh Prabu Gajah Agung yang berkedudukan di Cicanting. Sistem pergantian raja di Sumedanglarang dilakukan secara turun-temurun. Akan tetapi ibu kota kerajaannya menempati lokasi yang berpindah-pindah, seperti dari Cicanting kemudian berpindah ke Cipameungpeuk, Ciguling, dan Kutamaya yang ditempati oleh Pangeran Santri dan Prabu Geusan Ulun (Danasasmita, 1983/1984: 55).

Selama Geusan Ulun berkuasa, wilayah Sumedanglarang meliputi Sumedang, Garut, Tasikmalaya, dan Bandung. Dengan demikian, Tatar Ukur pun masuk ke dalam wilayah Sumedanglarang. Setelah Prabu Geusan Ulun wafat (1601), Kerajaan Sumedanglarang terpecah menjadi dua. Pertama diperintah oleh Ranggagede putra sulung dari Nyi Mas Gedengwaru yang pusat kotanya terletak di Dayeuhluhur (orang menyebutnya Canukur). Kerajaan kedua dipimpin oleh Pangeran Suriadiwangsa putra Harisbaya dari Pangeran Girilaya. Ibu kotanya terletak di Tegalkalong. Sepeninggal Prabu Geusan Ulun, di Sumedanglarang terjadi perubahan status pemerintahan. Bersamaan dengan itu, kedudukan Mataram semakin menguat. Pada 1614, VOC mengirim utusan ke Mataram yang waktu itu di bawah kekuasaan Sultan Agung. Sultan Agung mengklaim bahwa seluruh

\footnotetext{
${ }^{5}$ http://jelajahgunungbandung.com/menuju-7puncak-gunung-bandung/, diakses 31 Desember 2015, jam 15.00
} 
wilayah Jawa Barat kecuali Banten dan Cirebon berada di bawah kekuasaannya. Klaim Sultan Agung tersebut membuat Raden Suriadiwangsa ketakutan. Atas kemauannya sendiri Raden Suriadiwangsa datang ke Mataram menyatakan pengakuannya bahwa Sumedang berada di bawah kekuasaan Mataram (Muhsin, 2008: 11). Karena Sumedang berada di bawah kekuasaan Mataram, pada 1620 Tatar Ukur pun jatuh ke tangan Mataram (Hardjasaputra, 1998: 5).

Dengan keinginannya sendiri, Pangeran Suriadiwangsa mengakui kekuasaan Mataram, Sultan Agung memberinya gelar Pangeran Dipati Rangga Gempol Kusumahdinata (Rangga Gempol I). Semenjak itu status Sumedang yang semula berupa Kerajaan Sumedanglarang berubah menjadi sebuah kabupaten bagian dari Kesultanan Mataram. Rangga Gempol, selain diangkat bupati juga diangkat sebagai koordinator para bupati lainnya yang ada di wilayah Priangan atau yang lebih dikenal dengan istilah bupati wedana (Lubis, 2008: 124-125).

Dalam rangka ekspansi wilayah ke daerah timur, Sultan Mataram memerintahkan Rangga Gempol I untuk menaklukkan daerah Sampang Madura. Jabatan penguasa Sumedang diserahkan kepada adik tirinya yaitu Rangga Gede (putra dari istri Nyi Gedeng Waru). Selama Rangga Gede menjabat sebagai bupati, ia dapat menyatukan Sumedang yang pernah terbelah. Selama Pangeran Rangga Gede menjadi bupati, terjadi beberapa peristiwa penting di antaranya Raden Suriadiwangsa minta bantuan Banten untuk menyerang Sumedang dan serangan Mataram ke Batavia. Putera Pangeran Dipati Rangga Gempol Kusumahdinata bernama Ariadiwangsa merasa kecewa, disebabkan jabatan bupati diserahkan kepada Rangga Gede. Menurutnya, ia yang paling berhak menjadi putra mahkota. Atas keinginannya, ia pergi ke Banten untuk meminta bantuan. Ariadiwangsa memberikan janji kepada Sultan Banten apabila
Ariadiwangsa dapat naik tahta, maka Priangan akan tunduk kepada Banten. Banten yang bercita-cita ingin menguasai Sumedang tidak merasa keberatan. Mendengar Ariadiwangsa menjalin hubungan dengan Banten, Sultan Agung memanggil Rangga Gede dan menuduhnya sebagai bupati yang tidak bisa mengendalikan pemerintahan. Rangga Gede kemudian mendapatkan hukuman dan diberi sanksi yaitu jabatan sebagai bupati wedana $\operatorname{dicopot}^{6}$ dan jabatan tersebut diberikan kepada Dipati Ukur (Lubis, 2008: 128) dengan syarat Dipati Ukur mau membantu Mataram mengusir Kumpeni di Batavia. Seandainya Sultan Agung dapat mengusai Batavia, posisi Batavia sangat menguntungkan Mataram, karena letaknya strategis sebagai jalur perdagangan. Untuk memenuhi keinginannya, Sultan Agung membutuhkan dukungan dari Priangan karena daerah ini berbatasan langsung dengan Batavia.

Selama menggantikan Pangeran Ranggagede (1627), Dipati Ukur menikah dengan Nyi Ageng Alia atau Nyi Gedeng Ukur sebagai ahli waris Ukur. Wilayah yang ada dalam kekuasaan Dipati Ukur meliputi Sumedang Larang, Karawang, Pamanukan, Ciasem, Indramayu, Sumedang, Sukapura, Limbangan, dan Timbanganten (Anggapraja, 1978: 67-68).

\section{b. Perjuangan Dipati Ukur}

Ekspansi wilayah yang dilakukan oleh Sultan Agung adalah menyerang Banten. Akan tetapi untuk menyerang Banten telah terhalang oleh keberadaan VOC di Batavia yang sedang membuat benteng pertahanan. Untuk itu Sultan Mataram menghendaki Dipati Ukur yang telah diangkat oleh Sultan Mataram sebagai bupati wedana di Priangan sanggup membantu Sultan Mataram untuk mengusir VOC di Batavia. Guna menye-

\footnotetext{
6 Tindakan Sultan Agung mencopot jabatan bupati wedana Priangan tersebut disebabkan keinginannya menjadikan Priangan sebagai benteng pertahanan terdepan guna membendung Kumpeni dan Banten menguasai Batavia.
} 
rang VOC, Sultan Agung melakukan berbagai persiapan, disebabkan jalan dan hutan yang harus dilalui belum memadai.

Pada 1628, Sultan Agung memerintahkan Dipati Ukur dan Bahureksa untuk menggempur VOC di Batavia. Dalam perjanjian awal pasukan Dipati Ukur akan digabungkan dengan pasukan Mataram yang dipimpin oleh Bahureksa untuk bertemu di Karawang. Usai perjanjian tersebut, Dipati Ukur membawa pasukan 10.000 . Prajurit yang ikut serta merupakan prajurit pilihan dari sembilan umbul, yaitu Umbul Batulayang, Umbul Saunggatang, Umbul Taraju, Umbul Kahuripan, Umbul Medangsasigar, Umbul Malangbong, Umbul Manenggel, Umbul Segaraherang, dan Umbul Ukur. Mereka pergi dari Tatar Ukur, kemudian melewati Cikao (sekarang masuk wilayah Purwakarta) kemudian belok ke arah utara sampai ke Karawang (Mangle, 16-22 Juni 2016: 13).

Dalam rangka mengusir VOC di Batavia, Dipati Ukur sudah terlebih dahulu tiba di Karawang dibandingkan dengan rombongan Bahureksa. Setelah menunggu sekitar tujuh hari, rombongan Bahureksa belum juga datang. Dengan pertimbangan kekuatan VOC tidak begitu besar, Dipati Ukur dan rombongan akan dapat mengalahkannya. Ditunggu hingga keesokan harinya, Bahureksa dan rombongan belum juga tiba, rombongan Dipati Ukur memutuskan untuk pergi ke Batavia. Sesampai di Batavia, Dipati Ukur mengatur strategi dan siasat penyerangan. Kumpeni yang mendapat serangan mendadak menjadi panik, namun akhirnya kumpeni dapat menguasai keadaan dan mempersiapkan diri untuk bertempur.

Pada 11 September 1628, Pasukan Dipati Ukur mulai menggali garis pertahanannya ke arah depan mendekati Kota Batavia. Garis pertahanan tersebut diperkuat dengan kayu dan tumpukan tanah. Pembangunan garis pertahanan ini memakan waktu setengah bulan. Pada 12 September 1628, secara mendadak VOC membalas serangan ke arah garis pertahanan pasukan Dipati Ukur. Atas serangan VOC, pasukan Dipati Ukur bergerak mundur dari garis pertahanan. Garis pertahanan Dipati Ukur tersebut dirusak oleh VOC. Dari pertempuran tersebut, prajurit Dipati Ukur kewalahan dan banyak yang gugur.

Pada 21 Oktober 1628, di bawah komando Letnan Kolonel Jacques de Febure dilakukan serangan besar-besaran ke markas Dipati Ukur. Pasukan ini dipecah menjadi beberapa kelompok dan menyerang pasukan Dipati Ukur dari beberapa arah. Dipati Ukur tidak mampu menahan serangan tersebut dan terdesak mundur. Kekalahan Dipati Ukur disebabkan kondisi senjata yang tidak seimbang. Pasukan VOC memiliki senjata mutakhir sedangkan Dipati Ukur hanya memiliki senjata yang masih sederhana, akhirnya pasukan Dipati Ukur mundur ke Gunung Pongporang. Sejak kekalahan tersebut Dipati Ukur memutuskan untuk tidak mau lagi mengabdi kepada Mataram.

Tumenggung Bahureksa, yang mendapat tugas mengusir VOC dari Batavia, menempuh perjalanan dari Mataram, Cirebon, Karawang dan Batavia (Kutoyo, 1986: 76). Sesampai di Karawang, Bahureksa tidak menemukan Dipati Ukur dan rombongannya. Bahureksa segera menuju ke Batavia dan melangsungkan serangan terhadap Kumpeni. Bahureksa mengalami kekalahan dan mundur ke Karawang. Di Karawang Bahureksa masih juga tidak bertemu dengan Dipati Ukur. Sambil beristrahat Bahureksa mencari tahu mengenai keberadaan Dipati Ukur. Apakah Dipati Ukur sudah kembali ke Tatar Ukur atau bersembunyi di hutan. Setelah mendapatkan informasi yang jelas mengenai keberadaan Dipati Ukur, Bahureksa pulang ke Mataram. Adapun Dipati Ukur yang masih berada di Gunung Pongporang mengadakan musyawarah bersama pengikutnya. Dipati Ukur mengambil keputusan agar mereka tetap bertahan di Gunung Pongporang. Di Gunung Pongporang 
inilah Dipati Ukur berencana akan menyerang Mataram yang diperkirakan Sultan Mataram sedang berkonsentrasi untuk menyerang Batavia. Namun rencana Dipati Ukur tidak menghasilkan kata sepakat disebabkan keempat pengikut Dipati Ukur menginginkan untuk tidak berlama-lama di Gunung Pongporang, sedangkan Dipati Ukur menginginkan untuk bertahan. Keempat umbul tersebut adalah Umbul Sukakerta. Umbul Sindangkasih, Umbul Cihaurbeuti, dan Umbul Indihiang Galunggung. Karena tidak ada kata sepakat, keempat umbul tersebut meninggalkan Gunung Pongporang dan melanjutkan perjalanannya ke Mataram (Lubis, 2003; 15).

Di Mataram, Bahureksa melapor ke Sultan Agung atas kekalahannya dalam melakukan penyerangan ke Batavia. Ia juga menceritakan, ketika sampai di Karawang hingga selesai melakukan penyerangan, ia tidak menemukan Dipati Ukur. Bahureksa beranggapan bahwa kekalahan tersebut akibat dari kurangnya kekuatan. Kekalahan Bahureksa dalam melakukan penyerangan kepada VOC membuat Sultan Mataram kecewa. Kekecewaan Sultan Agung bertambah ketika keempat umbul pengikut Dipati Ukur telah sampai di Mataram. Pada saat menghadap sultan, keempat umbul tersebut melaporkan tentang kekalahan Dipati Ukur dan tempat persembunyiannya di Gunung Pongporang.

\section{c. Akhir Perjuangan}

Sultan Agung yang mendengar laporan dari Bahureksa yang merasa dikecewakan oleh Dipati Ukur, hatinya merasa gundah. Ditambah dengan adanya laporan dari keempat umbul pengikut Dipati Ukur yang juga gagal dalam melakukan penyerangan terhadap VOC di Batavia. Atas kekecewaannya tersebut, Sultan Agung mengutus Bahureksa untuk menangkap Dipati Ukur. Adapun keempat umbul tersebut dijadikan sebagai penunjuk jalan. Karena pasukan Bahureksa jumlahnya lebih banyak, pasukan Dipati Ukur pun terdesak. Dipati Ukur dan pengikutnya berhasil meloloskan diri dan bersembunyi di Gunung Lumbung, masuk daerah Batulayang Bandung.

Di Gunung Lumbung Dipati Ukur diikuti oleh pengikutnya sebanyak 1.000 orang. Di tempat persembunyian di Gunung Lumbung, Dipati Ukur membuka sawah dan tegalan (Ekadjati, 1977: 31). Pada saat Dipati Ukur bersembunyi di Gunung Lumbung, pasukan Mataram melakukan penyerangan. Pasukan Dipati Ukur pun membalas perlawanan tersebut. Narapaksa pimpinan pasukan Mataram tidak dapat menahan balasan serangan dari pasukan Dipati Ukur, sehingga Dipati Ukur dan pasukannya dapat terselamatkan. Pada pertengahan 1632, Tumenggung Narapaksa bertemu dengan orang yang hafal jalan menuju Gunung Lumbung. Ia menaiki Gunung Lumbung dan melakukan penyerangan. Disusul pasukan Sutapura yang juga naik ke atas gunung untuk melakukan penyerangan. Terjadilah peperangan antara pasukan Mataram dan pasukan Dipati Ukur. Akibat peperangan tersebut korban berjatuhan dari kedua belah pihak. Dipati Ukur terdesak dan dapat meloloskan diri. Pengikut Dipati Ukur ada yang kembali ke rumah masingmasing dan ada pula yang terus mendampinginya.

Untuk mengelabui kejaran pasukan Mataram, pengikut Dipati Ukur membuat gundukan tanah yang menyerupai kuburan. Gundukan tersebut oleh pengikutnya diberi nama Wangsanata dari Priangan. Hal itu dilakukan agar pasukan Mataram mengira bahwa Dipati Ukur telah mati terbunuh (Setiawan, 2006: 101). Dengan demikian masyarakat pun beranggapan bahwa makam Dipati Ukur ada di beberapa tempat.

\section{Jejak Peninggalan Dipati Ukur}

Dipati Ukur dan pengikutnya bertahan di Gunung Pongporang tidak tahan lama. Terjadi konflik intern antara Dipati Ukur yang ingin tetap bertahan dengan keempat umbul pengikutnya yang 
menginginkan keluar dari Gunung Pongporang. Konflik tidak dapat dielakkan. Keempat umbul pengikutnya akhirnya memisahkan diri dan pergi ke Mataram. Keempat umbul inilah yang kemudian menjadi penunjuk jalan pasukan Bahureksa yang diutus Sultan Agung untuk menangkap Dipati Ukur. Akan tetapi Dipati Ukur dapat meloloskan diri dan bersembunyi di Gunung Lumbung. Di Gunung Lumbung Dipati Ukur membuat perkampungan. Jejak tinggalan tempat persembunyian Dipati Ukur berupa patung yang berserakan, batu, lingga, dan patung batu yang telah rusak (Lubis, 2003: 15).

Kegagalan dalam usaha untuk menangkap Dipati Ukur di Gunung Lumbung, tidak membuat Bahureksa putus asa. Bahureksa dan pasukannya terus mencari dan mengejar tempat persembunyian Dipati Ukur. Dipati Ukur yang telah berhasil meloloskan diri dari kepungan pasukan Bahureksa pergi berpindah-pindah ke berbagai tempat di Kabupaten Bandung dan meneruskan perjuangannya melawan tentara Mataram. Untuk mengetahui tentara Mataram yang terus mengejarnya, Dipati Ukur menyamar sebagai rakyat biasa.

Dalam penyamarannya di daerah Cililin, Dipati Ukur luput dari kejaran tentara Mataram. Justru yang tertangkap oleh tentara Mataram adalah seseorang yang mirip Dipati Ukur. Peninggalan Dipati Ukur tersebar ada yang di Cililin, Gunung Halu, Soreang, dan Cibodas Lembang. Dipati Ukur menjadi seorang pendeta yang makamnya dianggap keramat oleh masyarakat sekitarnya. Makamnya terdapat di puncak sebuah bukit di Banjaran Kabupaten Bandung (Lubis, 2003: 16).

Selain di Cililin dan Banjaran, beberapa peninggalan yang ada kaitannya dengan Dipati Ukur, seperti lokasi ibu kota, makam, senjata, piagam, patung, dan lain-lain. Peninggalan-peninggalan tersebut adalah: a) lokasi ibu kota daerah Ukur terletak di Pabuntelan termasuk Desa Tenjonagara Kecamatan Pacet Kabupaten Bandung. Pada masa lalu, di desa tersebut masih berupa makam, namun sekarang sudah tidak ada lagi, barangkali hanya tinggal kuburan dan kepercayaan; b) lokasi benteng (yaitu di Gunung Lumbung yang terletak di sebelah barat laut Kota Bandung sekarang termasuk Kecamatan Cililin Kabupaten Bandung); c) tempat yang dianggap kuburan Dipati Ukur, yang menurut kepercayaan masyarakat setempat ada di wilayah mereka dan dipercaya sebagai makam Dipati Ukur (yaitu Astana Luhur di Desa Bojongmanggu Pameungpeuk); d) puncak Gunung Geulis (perbatasan Desa Manggahang dan Rancakole Ciparay), e) tepi Sungai Citarum (Desa Manggahang); f) Gunung Sadu Soreang; g) Kampung Cikatul (Pabuntelan Desa Tenjonagara Kecamatan Pacet); h) Astana Handap (Banjaran); i) Gunung Tikukur (Desa Manggahang); dan j) Pasir Luhur (Ujungberung Utara) (Ekadjati dalam Rohendi Somadinata dan Supir, 1979: 39) Dalam Ensiklopedi Sunda disebutkan bahwa kuburan Dipati Ukur ada di Ujungberung, Ciparay, dan Banjaran (Rosidi, 2000: 196).

Suhendar, salah satu warga di Desa

Pakutandang Kecamatan Ciparay Kabupaten Bandung mengatakan bahwa di Kecamatan Ciparay terdapat beberapa peninggalan Dipati Ukur. Keterangan Suhendar yang diperoleh secara turuntemurun tersebut mengatakan bahwa di Kecamatan Ciparay Dipati Ukur melakukan perjuangannya ketika melawan tentara Mataram (wawancara dengan Suhendar, 21 Agustus 2016). 


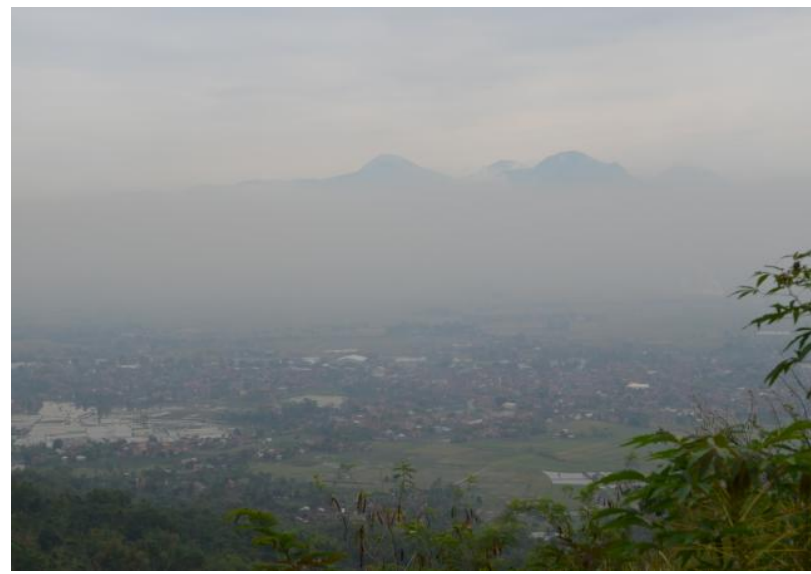

Gambar 1. Kawasan Ciparay tempat perjuangan Dipati Ukur Sumber: Lasmiyati, 2016

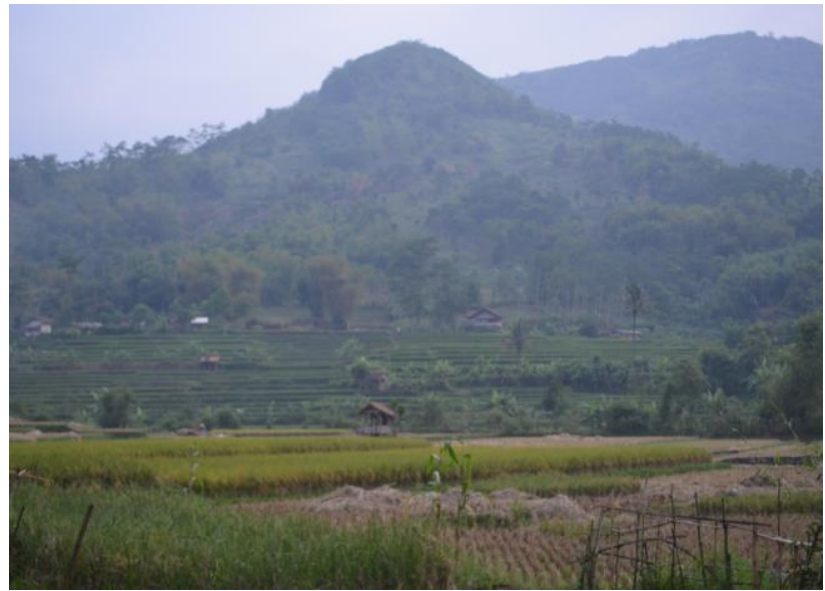

Gambar 2: Bukit Cula

Sumber: Lasmiyati, 2016

Adapun menurut penuturan Endang Tarsa atau yang biasa dipanggil Abah Umar, bahwa pengembaraan Dipati Ukur ke wilayah Ciparay khususnya di Bukit Cula ini dilakukan menjelang Dipati Ukur meninggal. Di kawasan Bukit Cula, Dipati Ukur membangun pemukiman yang letaknya di sebuah bukit bernama Bukit Cula.

Pada awal abad ke-17, Bekas Culanegara digunakan sebagai tempat pertahanan kekuasaan Dipati Ukur sebelum ia mengakhiri serangannya terhadap pasukan Mataram. Kawasan tempat menyimpan benda pusaka milik Dipati Ukur bernama Imah Leutik dan disamarkan menjadi Gunung Leutik. Adapun Imah Gede yang ada di
Culanegara dinamakan kadaleman yang disamarkan menjadi Gunung Cula (yang sekarang dikenal dengan nama Bukit Cula). Adapun Gunung Leutik pada saat ini menjadi sebuah desa (wawancara dengan Endang Tarsa, 3 September 2016).

Nama-nama yang ada di Desa Gunung Leutik Kecamatan Ciparay tersebut memiliki kaitan dengan jejak Dipati Ukur. Seperti halnya dengan sebutan raden untuk sebutan Dipati Ukur, nama raden akhirnya dijadikan menjadi nama sungai yaitu Sungai Ciraden yang membatasi antara Calengka Desa Buniwangi dan Gunung Leutik (wawancara dengan Endang Tarsa, 3 September 2016). 
Di Bukit Cula terdapat tiga puncak yaitu Puncak Ramogiling (batu korsi), dahulunya merupakan tempat singgasana (tempat duduknya) Dipati Ukur. Kedua, Puncak Leuit Salawe Jajar. Leuit adalah sebuah bangunan yang dijadikan tempat untuk menyimpan padi. Leuit tersebut berjumlah dua puluh lima jajar (baris). Satu jajar berisi 25 lumbung (leuit). Jadi leuit tersebut berjumlah 625 lumbung. Padi sengaja disimpan di leuit untuk persediaan bahan makanan bagi pejuang Dipati Ukur dan untuk rakyat yang berada di sekitar kawasan tersebut. Leuit yang berjumlah 25 jajar tersebut menggambarkan bahwa persediaan bahan makanan milik Dipati Ukur dapat mencukupi para pengikutnya. Saat ini, Leuit Salawe Jajar hanya berupa rerimbunan di tepian bukit (wawancara dengan Suhendar, 21 Agustus 2016). Puncak ketiga, adalah Puncak Bakiculah (Baranangsiang). Tidak jauh dari Ramogiling terdapat kadaleman yang diperkirakan dahulunya sebagai tempat tinggal Dipati Ukur, dan pamoyan yang dijadikan sebagai tempat moyan.

Petilasan lainnya adalah Kampung Leo Madur (madur) adalah tempat berbuat sesuatu kepada Yang Widhi (Madura). Ada Kampung Tenjonagara, Kampung Pangauban (tempat berkumpul), dan Kampung Pabuntelan. Di Kampung Pabuntelan ini Dipati Ukur mempreteli pakaiannya, kemudian di-buntel sebab Dipati Ukur dikejar-kejar oleh tentara Mataram. Saat dikejar-kejar oleh tentara Mataram Dipati Ukur melarikan diri sampai ke Cisanti (Gunung Wayang) dan Gunung Puntang.

Di Kecamatan Ciparay inilah Dipati Ukur menyamar sebagai rakyat biasa, bahkan ia sempat melucuti pakaian kebesaran kadaleman untuk kemudian diganti dengan pakaian rakyat kebanyakan. Pada salah satu asesoris pakaian kebesarannya tersebut terselip sebuah benda pusaka berupa duhung atau keris yang bernama culanagara $^{7}$ yang hingga saat ini dijadikan sebagai benda peninggalan Dipati Ukur. Pakaian kebesaran tersebut kemudian disimpan di galian tanah yang hingga saat ini tempat galian tersebut dijadikan sebagai situs sejarah bernama Situs Culanegara persisnya berada di sebuah bukit Gunungleutik Kecamatan Ciparay Kabupaten Bandung. Bahkan di area situs tersebut juga didirikan palagan (monumen) bernama Palagan Culanagara.

Palagan Culanagara dibangun pada 2012 dan mendapat dukungan dari Pemerintah Kabupaten Bandung. Palagan tersebut dibangun di sebuah bukit, oleh Pemerintah Kabupaten Bandung diberi nama Situs Bukit Cula.

Masih menurut Suhendar, Situs Bukit Cula ini juga merupakan sebuah kawasan yang bernama kawasan Culanagara. Kawasan ini merupakan kadaleman tempat petilasan markas perjuangan gerilya Dipati Ukur yang terletak di Bukit Cula. Duhung yang disimpan di tempat tersebut merupakan warisan terakhir dari Raja Pajajaran Prabu Surakancana Sang Nursia Mulya, yaitu sebagai sebuah amanat untuk menjaga dan mempertahankan tanjeur Pajajaran pasca Pajajaran runtuh. Amanat tersebut sempat dijalankan oleh Dipati Ukur ketika berhasil menguasai wilayah Tatar Sunda sebagai wedana bupati menggantikan Rangga Gempol. Bahkan di kawasan Culanagara ini Dipati Ukur pernah melakukan rapat atau musyawarah guna melakukan penyerangan terhadap musuh (wawancara dengan Suhendar, 21 Agustus 2016).

\footnotetext{
${ }^{7}$ http://bandungkabmozaik.com.
} 


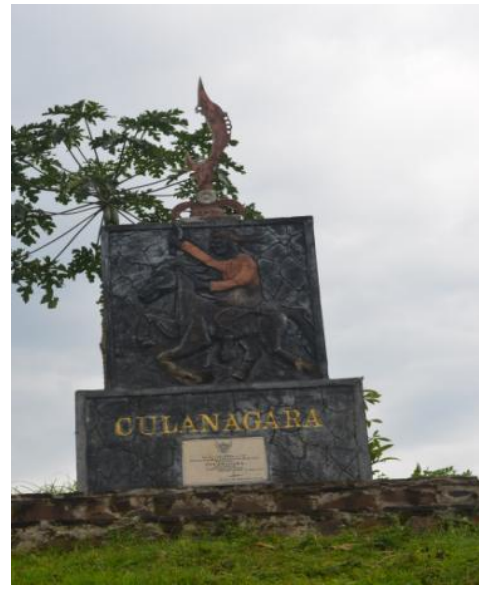

Gambar 3. Palagan Culanagara Sumber: Lasmiyati, 2016.

Saat ini palagan yang lokasinya berdekatan dengan pemakaman umum tersebut dijadikan sebagai tempat dudukduduk masyarakat sekitar, mereka ngobrol sambil bercengkerama.

Kawasan berikutnya yang dijadikan sebagai tempat tinggal Dipati Ukur adalah Kadaleman. Kadaleman yang diambil dari kata dalem tersebut artinya rumah atau istana. Diperkirakan Dipati Ukur juga pernah membuat tempat tinggal di wilayah ini. Selain itu di kawasan tersebut juga terdapat peninggalan berupa batu di antaranya Batu Ramogiling. Ramogiling yaitu sebuah tempat yang dijadikan sebagai tempat pengamanan atau tempat persembunyian para pejuang Dipati Ukur. Bahkan di perkampungan yang saat ini berada di bawah Bukit Cula diberi nama Kampung Pamupusan. Diberi nama pamupusan disebabkan seandainya pejuang Dipati Ukur yang dikejar musuh bersembunyi di Kampung Pamupusan, musuh tidak dapat menemukannya. Peninggalan lainnya adalah Batu Palalangon (Sungkawa, 2013: 42). Di tempat tersebut oleh Dipati Ukur dan para pejuang lainnya palalangon dijadikan sebagai tempat bersantai.

Selain itu juga terdapat Batu Korsi. Batu ini berada di puncak pertama, berfungsi sebagai tempat istirahat. Di depan batu terdapat bekas telapak kaki. Saat ini, lahan di sekitar Batu Korsi dijadikan tempat terbuka untuk umum. Kesaksian Suhendar bahwa apabila dudukduduk pada Batu Kursi tersebut pakaian tidak akan kotor. Batu lainnya adalah Batu Bandera. Batu Bandera awalnya bernama Batu Barera, yaitu tempat untuk memberikan informasi kepada penguasa di Kadaleman (Ramogiling) melalui simbol gerakan bendera (Umar, 2012: 11).

Jejak petilasan lainnya adalah terdapat di Pasir Gunung Leutik Kecamatan Ciparay, yaitu undakan Batu Sindang Panon, yaitu tempat untuk mengatur strategi pasukan dalam pengamanan perang. Lapang Barjati yaitu lapangan untuk kegiatan latihan ketentaraan. Cipaku dahulunya tempat kediaman para abdi. Pangkalan yaitu tempat pendatang dari Kerajaan Timbanganten yang akan menggarap lahan sesudah ditinggalkan oleh Dipati Ukur. Barugbug yaitu tempat menyimpan peralatan menggarap lahan. Cebrek yaitu tempat atau jalan yang selalu basah dan berlumpur yang duhulunya oleh Dipati Ukur dijadikan untuk batas pertahanan (Umar, 2012: 12).

Selama Dipati Ukur bermukim di Bukit Cula tersebut, Bahureksa dan pengikutnya terus mengejar Dipati Ukur hingga ke tempat persembunyiannya. Sementara Dipati Ukur pun terus melakukan perlawanan secara bergerilya dan berpindah dari satu tempat ke tempat lain. Dipati Ukur berpindah lagi ke arah barat yaitu ke tanah Bungbang yang ada di wilayah Cengkareng Banten. Akan tetapi dengan alasan demi keselamatan anak buahnya, Dipati Ukur memutuskan berdamai dengan Mataram. Dipati Ukur dan umbul lainnya langsung berhadapan dengan Bahureksa. Bahureksa sangat menghargai keputusan Dipati Ukur, ia pun berharap Sultan Agung dapat mengampuni. Namun Sultan Agung menjatuhi hukuman mati.

Perjuangan Dipati Ukur berakhir pada 1632 M. Dipati Ukur meninggal dunia pada 1633. Dengan meninggalnya Dipati Ukur, ia masih menyisakan 1.000 
kepala keluarga yang pernah ikut berperang di Batavia. Ia juga meninggalkan daerah-daerah yang pernah dikuasainya.

\section{Reorganisasi Wilayah}

Dengan berakhirnya perlawanan Dipati Ukur 1632/1633 M. kehidupan di Priangan menjadi sepi. Bekas-bekas kerusakan terjadi di daerah-daerah bekas perlawanan Dipati Ukur. Untuk itu Sultan Agung menganggap perlu adanya stabilitas dan mengangkat para umbul yang dahulunya pernah berjasa. Sehingga dikeluarkanlah reorganisasi wilayah Priangan dengan membagi-bagi wilayah atas beberapa pusat kekuasaan yang dipimpin oleh bangsawan lokal yang disebut Mantri Agung yang nantinya disebut bupati. Pengangkatan tersebut tertuang dalam Serat Piyagem yang berbunyi sebagai berikut:

"Penget serat piagem Sultan Mataram, kagaduhaken dening kiai Ngabehi Wirawangsa kang prasetya dateng ingsun, sun jenengaken Tumenggung Wiradadaha Sukapura, sun jenengaken Mantri Agung Wiraangun-angun Bandung, Tumenggung Tanubaya Parakanmuncang, kang sami prasetya maring ingsun.

Lan leleraning ratu kampung velongsong ratna kumambang, lan duhung sampana kinjeng, lan kolambi kandaga lante, payung bawat, lan kuda titihan serta titiyang kawulaning ratu, wadana kalih serta desane wong tigang atus den perdikaken tigang taun, dening sultan. Kang kalebetaken ing serat puniko, panembahan ratu Cirebon, Pangeran Kajoran, Pangeran Madiun, Pangeran Puragabaya, Patih Mataram sakawan, Ki Tumenggung Wiraguna, Ki Tumenggung Tanpasisingan, Ki Tumenggung Selarong, Ki Tumenggung Singranu. Kala anurat hing dino Sabtu ping sanga wulan Muharam tahun Alip, kang anurat abdining ratu pun carik.
Artinya:

Piagam dari saya Sultan Mataram diberikan kapada Ngabehi Wirarangsa yang tetap setia kepada saya. Saya mengangkat Tumenggung Wiradadaha menjadi Mantri Agung di Sukapura, Tumenggung Wiraangun-angun menjadi Mantri Agung di Bandung, dan Tumenggung Tanubaya menjadi Mantri Agung di Parakanmuncang yang juga menjadi tetap setia kepada saya. Sultan sendiri mengacungkan tangannya dan berkata: Semua bergembiralah bersoraklah tujuh kali dan bunyikan gamelan. Dan pemberian sultan ialah pakaian seragam kenegaraan, sebuah keris Sampana Kinjeng, sebuah keris Ratua Kumambang, sebuah pipah, peti, tikar, payung bawat, kuda, dan abdi-abdi raja, terdiri atas 12 wedana dan 300 rakyat. Aku membebaskan mereka dari kewajibankewajiban kepada Raja Mataram, sebagaimana telah ditentukan dalam buku: Panembahan Cirebon, Pangeran Kajoran, Pangeran Blitar, Pangeran Madiun, Panembahan Surabaya, Keempat Patih Mataram, Tumenggung Wiraguna, Tumenggung Tanpasiringan, Tumenggung Saloran, dan Tumenggung Singaranu.

(ditulis pada hari Sabtu tanggal 9 Muharam tahun Alip oleh juru tulis raja (Lubis, 2003: 16-17).

Setelah mendapat surat pengangkatan dari Mataram, Tumenggung Wiraangunangun kembali ke Tatar Ukur, tepatnya ke Timbanganten. Ia mendapatkan 200 cacah. Selanjutnya ia membangun pusat pemerintahan di daerah Krapyak/ Bojongasih yang terletak di tepi Sungai Citarum, dekat muara Sungai Cikapundung. Daerah Krapyak dan sekitarnya inilah sering disebut dengan Bumi Ukur Gede.

Susuhunan Mataram tidak menginginkan wilayah kekuasaan Dipati Ukur menjadi kosong. Susuhunan memanggil Mantri Cihaurbeuti Raden Astramanggala. Ia menerima sembilan daerah dari 
Ukur Bandung agar mendirikan kota dan mendapat tambahan 200 keluarga dari Timbanganten. Selanjutnya dibagi ke dalam beberapa kepala seperti Umbul Kahuripan, Umbul Pasir Panjang, Umbul Kedongora (Kadungora), dan Mas Naraya (dari Batulayang). Susuhunan Mataram memerintahkan agar semuanya berpindah ke Bandung untuk mengurus kuda-kuda Susuhunan). Mereka kemudian menempati sebelah timur Sungai Cikapundung yang kemudian tempat tersebut diberi nama Krapyak (Anggapraja, 1978: 70-71).

\section{PENUTUP}

Nama Dipati Ukur begitu melegenda. Ia memiliki jiwa keberanian ketika melawan VOC di Batavia. Dipati Ukur mengalami kekalahan. Selain kalah dalam kemutakhiran senjata, VOC ahli dalam mengadu domba. Begitu tokoh pribumi akan mendapatkan kemenangan, VOC segera melakukan perundingan yang merugikan tokoh pribumi.

Begitu pula dengan Dipati Ukur. Ketika ia melakukan penyerangan kepada VOC, Dipati Ukur pun mengalami kekalahan. Untuk menghindari bentrokan dengan pasukan Bahureksa, Dipati Ukur memilih untuk bersembunyi dari tempat satu ke tempat lain. Di tempat persembunyiannya itulah Dipati Ukur membuat perkampungan, membuka lahan, berkebun, dan bersawah. Di tempat itulah nantinya menjadi tempat petilasan dan meninggalkan barang peninggalan, baik berupa batu atau pun tembikar.

Salah satu bentuk peninggalan Dipati Ukur yang ada adalah Situs Bukit Cula yang berlokasi di Gunung Leutik Kecamatan Ciparay Kabupaten Bandung. Di situ Dipati Ukur pernah menyamar sebagai rakyat biasa. Ia menanggalkan pakaian kebesarannya dan duhung yang merupakan senjata kepunyaan raja Pajajaran terakhir. Tempat penyimpanan pakaian dan senjata di Bukit Cula yang kemudian dikenal dengan Situs Bukit Cula. Bahkan di bukit tersebut juga terdapat sebuah Palagan Culanagara dan pening- galan batu. Di Bukit Cula, Dipati Ukur mendirikan perkampungan dan kadaleman. Guna memenuhi kebutuhan seharihari, Dipati Ukur membuat lumbung padi yang dikenal dengan nama Leuit Salawe Jajar. Peninggalan lainnya adalah berupa batu yang dahulu pernah digunakan oleh Dipati Ukur sebagai kursi (Batu Korsi).

Akan tetapi Situs Bukit Cula yang berlokasi di Desa Gunung Leutik Kecamatan Ciparay Kabupaten Bandung ini kurang dikenal oleh masyarakat disebabkan tidak adanya petunjuk jalan atau plang untuk menuju situs tersebut.

Walaupun demikian, bagi masyarakat Bandung dan sekitarnya, nama Dipati Ukur sudah tidak asing lagi. Begitu melekatnya di hati masyarakat Bandung dan sekitarnya, pemerintah setempat pun mengenangnya dengan cara menetapkan nama Dipati Ukur untuk nama sebuah jalan.

Penelitian ini merupakan penelitian awal, masih diperlukan penelitian lanjutan, disebabkan masih kurangnya data atau referensi mengenai peninggalan Dipati Ukur.

\section{UCAPAN TERIMA KASIH}

Penulis mengucapkan terima kasih kepada Abah Umar Ketua Juru Pelihara se-Kabupaten Bandung yang telah memberikan informasi mengenai Dipati Ukur dan tempat peninggalannya, dan kepada semua pihak yang telah memberikan bantuan pada saat penelitian ini.

\section{DAFTAR SUMBER}

\section{Jurnal, Makalah}

Ekadjati, Edi. "Peninggalan Sejarah Jawa Barat dan Permasalahannya", Makalah. disampaikan dalam acara Gempungan Budaya Tingkat Provinsi Jawa Barat. 1987.

Priyadi, Soegeng. "Perdikan Cahyana", Jurnal Penelitian Humaniora. Vol. XIII No. 1 Februari 2001, hlm. 89-100. 


\section{Buku}

Anggapraja, Sulaeman. 1978. Sejarah Garut dari Masa ke Masa. tt.

Danasasmita,Saleh, Yoseph Iskandar, Enoch Atmadibrata. 1983/1984.

Rintisan Penelusuran Masa Silam, Sejarah Jawa Barat, 4. Jawa Barat: Proyek Penerbitan Sejarah Jawa Barat Pemprov Daerah Tingkat I.

Ekadjati, Edi. S. 1977.

Ceritera Dipati Ukur, Karya Sastra Sejarah Sunda. Bandung: Pustaka Jaya.

Kuntowijoyo. 2003.

Metodologi Sejarah, edisi kedua. Yogyakarta: Tiara Wacana.

Kutoyo, Sutrisno., Soewadji Sjafei, Boedi Soesilo, Maskuri, Suhartinah Sudiyono, Sri Sutjianingsih. 1986.

Sejarah Ekspedisi Pasukan Sultan Agung ke Batavia. Jakarta: Depdikbud Direktorat Jarahnitra Proyek IDSN.

Lubis, Nina Herlina., Mumuh Muhsin, Etty S Dyanti, Awaludin Nugraha, Mihtahul Falah. 2008.

Sejarah Sumedang dari Masa ke Masa. Sumedang: Dinas Pariwisata dan Kebudayaan Pemkab Sumedang.

Lubis, Nina Herlina. 2003.

Sejarah Kabupaten Bandung, Konsentrasi Kajian Kabupaten Bandung dalam Perspektif Sejarah. Bandung: Lembaga Pengabdian Kepada Masyarakat UNPAD bekerjasama dengan Badan Pengembangan Infomasi Daerah Kabupaten Bandung.

Rosidi, Ajip (ed). 2000.

Ensiklopedi Sunda, Alam, Manusia, dan Budaya, termasuk Budaya Cirebon dan Betawi. Jakarta: Pustaka Jaya.

Setiawan, A dan U, Syahbudin. 2006.

Dipati Ukur Ksatria dari Pasundan. Cerita Rakyat Jawa Barat. Bandung: Pustaka Setia.

Sumantri, Lily. 1973. Hari Jadi Kabupaten Bandung, 20 April 1641. tt.

Sjamsuddin, Helius. 2007. Metodologi Sejarah. Yogyakarta: Ombak.
Sungkawa, Dadan. 2013.

Mozaik Kabupaten Bandung, Telisik Artefak yang Berserak. Kabupaten Bandung: Dinas Pendidikan dan Kebudayaan Bidang Sejarah dan Kepurbakalaan.

Tim Penyusunan KBBI. 2011.

Kamus Besar Bahasa Indonesia, edisi keempat. Departemen Pendidikan Nasional. Jakarta: Gramedia Pustaka Utama.

Umar. 2013.

Kawasan Purbakala di Bukit Culah Situs Culanagara di Kecamatan Ciparay Kabupaten Bandung Jawa Barat. tt

Ziaulhaq, Muhammad, Asep Lukman Elgarsel. 2007.

Tatar Garut Historiografi Tradisional. Garut: Dinas Pariwisata dan Kebudayaan Kabupaten Garut.

\section{Surat Kabar/Majalah}

Anonim. 2016.

"Dipati Ukur", Mangle. Nomor 2582.

Tgl 16-22 Juni 2016, hlm. 13.

\section{Internet}

Hardjasaputra, Sobana. "Hari Jadi Kota Bandung", Lembaran Daerah Kotamadya Daerah Tingkat II Bandung No. 14 Seri D, tahun 1998 tentang Peraturan Daerah Kotamadya Daerah Tingkat II Bandung, Nomor 35 tahun 1998, diakses dari http://portal.bandung. go. id, pada 26 Oktober 2016, jam. 14.10.

2011, dalam "Sejarah Berdirinya Kabupaten Bandung", diakses dari $\mathrm{h} t t p: / / w w w$. bandungkab.go.id, tanggal 26 Oktober 2016, jam. 10.47.

Muhsin, Mumuh Z, dalam "Terbentuknya Keresidenan Priangan", diakses dari www. pustaka unpad.ac.id, tanggal 20 Maret 2008, jam. 13.48.

Umar, Abah, dalam "Situs Bukit Cula", diakses dari http: bandungkab mozaik.com, tanggal 3 Agustus 2016, jam. 14.33.

Unu, Mihardja, dalam "Menuju 7 Puncak Gunung Bandung", diakses dari jelajahggunungbandung.com, pada 31 Desember 2015, jam 15.00. 


\section{Sumber Lisan/Informan}

Suhendar (63 tahun). 2016.

Staf Desa Pakundang Kec. Ciparay Kab.

Bandung, wawancara, Kab. Bandung,

21 Agustus 2016.

Tarsa, Endang (Abah Umar) (65 tahun). 2016.

Ketua Penilik Juru Pelihara se-

Kabupaten Bandung, wawancara, Kab.

Bandung, 3 September 2016. 